\title{
A FORMAÇÃO CONTINUADA DO PROFESSOR NA CONTRIBUIÇÃO DA AUTONOMIA DO EDUCANDO
}

\section{ARTIGO ORIGINAL}

TEIXEIRA, Damares de Oliveira 1, SILVA, Dijandira Francisca Ferreira da 2, FONSÊCA, Elizabeth do Norte ${ }^{3}$, SILVA, Janaina Valentim da ${ }^{4}$, PEREIRA, Maria Jankeline Ferreira ${ }^{5}$, SOUZA, Maria Regilene Gonzaga de ${ }^{6}$, OLIVEIRA, Regis Flávio Varela de ${ }^{7}$

\footnotetext{
${ }^{1}$ Doutorado em Ciências da Educação (andamento); Mestrado em Ciências da Educação; Graduação em Pedagogia. ORCID: 0000-0002-0087-1717

2 Doutorado em Ciências da Educação (andamento); Mestrado em Ciências da Educação; Especialização em Psicopedagogia Clínica e Institucional; Graduação em Pedagogia. ORCID: 0000-0001$5349-8197$

3 Doutorado em Ciências da Educação (andamento); Mestrado em Ciências da Educação;
} Especialização em Gestão Escolar e Coordenação Pedagógica; Graduação em Pedagogia. ORCID: 00000001-5451-9076

${ }^{4}$ Doutorado em Ciências da Educação (andamento); Mestrado em Ciências da Educação; Graduação em Geografia. ORCID: 0000-0001-5857-4419

5 Doutorado em Ciências da Educação (andamento); Mestrado em Ciências da Educação; Especialização em Língua Brasileira de Sinais - Libras; Especialização em MBA em Gestão de Pessoas; Graduação em Serviço Social; Graduação em Letras - Língua Portuguesa; Graduação em Pedagogia. ORCID: 0000-0002-0036-2955

6 Doutorado em Ciências da Educação (andamento); Mestrado em Ciências da Educação; Especialização em Gestão Escolar e Coordenação Pedagógica; Especialização em Educação Infantil; Especialização em educação ambiental e geografia do semi-árido; Graduação em Pedagogia. ORCID: 0000-0002-8344-3397

${ }^{7}$ Orientador. ORCID: 0000-0003-1556-4717

RC: 105854

Disponível em: https://www.nucleodoconhecimento.com.br/educacao/autonomia-do-educando 
TEIXEIRA, Damares de Oliveira. Et al. A formação continuada do professor na contribuição da autonomia do educando. Revista Científica Multidisciplinar Núcleo do Conhecimento. Ano. 07, Ed. 01, Vol. 06, pp. 55-74. Janeiro de 2022. ISSN: 24480959, Link de

acesso: https://www.nucleodoconhecimento.com.br/educacao/autonomia-doeducando

\section{RESUMO}

A presente pesquisa trata de uma reflexão da formação continuada do docente como prática educativa na contribuição da autonomia do educando, desenvolvendo a criticidade, no intuito de motivar a edificação do conhecimento, levando o aluno a questionar, refletir, construir e transformar, refletindo essa prática educativa a favor da autonomia do educando. O ensino necessita de pesquisa e aperfeiçoamento constante do conhecimento, para elaboração de aulas dinâmicas e envolventes, por isso é importante a formação continuada e constante do educador no processo educacional, onde o professor não só aprende para ensinar, mas também para desenvolver habilidades que possam acrescentar na coletividade. Neste contexto, o presente artigo, tem como questão norteadora: Qual a participação do professor na construção da autonomia do aluno? Tendo como objetivo estudar a formação do educador na construção do saber e autonomia do educando, tendo em vista que a formação do professor proporciona a melhoria na aprendizagem dos alunos, refletindo sobre a importância da formação continuada do professor; a leitura na formação continuada deste e autonomia do educando. Para isto, adotou-se como metodologia de pesquisa o estudo bibliográfico. Como resultado, constatou-se que o professor precisa caminhar com a teoria e prática no ensino para construção da autonomia do educando; se aperfeiçoando em formações continuadas, motivando a criticidade, curiosidade, explorando conhecimentos prévios, valorizando a realidade em que 0 discente está inserido, bem como conhecendo suas necessidades para intervenção e construção da aprendizagem.

RC: 105854

Disponível em: https://www.nucleodoconhecimento.com.br/educacao/autonomia-do-educando 
Palavras Chaves: Formação continuada, professor, autonomia, educando.

\section{INTRODUÇÃO}

A formação continuada do professor é um processo de constante aperfeiçoamento para contribuir na educação do aluno. Desvelar a autonomia do educando exige saberes necessários a serem despojados com abundância de conhecimentos. Com isso, tornar o aluno protagonista com sua autonomia, é assegurar o ensino às novas metodologias para mediar o processo de ensino-aprendizagem.

Neste contexto, o presente artigo tem como questão norteadora: Qual a participação do professor na construção da autonomia do aluno? O educador tem papel fundamental na mediação do saber que leva a autonomia do educando. Um saber que induz a curiosidade, mas também a reflexão, a criticidade e a liberdade da própria construção do conhecimento.

Tratar sobre a formação continuada do professor para contribuir na independência do aluno em sua aprendizagem, é trazer ao centro, a defesa que ele pode desencadear conhecimentos a serem trabalhados em sala de aula a partir das suas intervenções em indagar o educando a criticidade, reflexão, ser curioso e buscar novas respostas, novos saberes.

Tendo em vista que o aluno está inserido em uma sociedade com divergências de reflexões e opiniões, surge a hipótese em assegurar que o professor deve estar em constante formação e que a educação do aluno pode ser direcionada a transformação de conhecimento através de reflexões críticas que muda os paradigmas da sociedade.

Com isso, entende-se que a formação continuada é indispensável a condução da educação reflexiva, fazendo com que o aluno esteja em um caminho ético e político, fazendo os indivíduos testemunhar seus pensamentos irrefutáveis, de que respeitamos suas opções em oposição às nossas.

RC: 105854

Disponível em: https://www.nucleodoconhecimento.com.br/educacao/autonomia-do-educando 
Como metodologia adotou-se a pesquisa bibliográfica. Tendo como objetivo estudar a formação do educador na construção do saber e autonomia do educando, refletindo sobre a importância da formação continuada do professor; a leitura na formação continuada deste e a autonomia do educando.

Propondo mostrar que a formação continuada é um importante elemento para expandir conhecimentos docente, de forma específica, entender com a leitura pode ajudar no processo de construção do saber do aluno, refletir sobre o ensinar para uma educação que seja reflexiva e transformadora e demonstrar a legitimidade de a formação para o professor inovar suas práticas e experiências, são os objetivos específicos do artigo.

\section{A IMPORTÂNCIA DA FORMAÇÃO CONTINUADA DO PROFESSOR}

Segundo Paulo Freire (2011), para que o docente tenha uma prática de excelência, faz-se necessário observar alguns critérios, como exemplo, é preciso que seja reflexivo, pesquisador, respeite os saberes dos estudantes, seja crítico, esteja aberto ao novo, seja reflexivo à sua prática, reconheça a identidade cultural do aluno, incentive a autonomia do discente e esteja disponível para o diálogo.

Essa postura remete as relações educativas de desenvolvimento favorável à criação a formação do professor para que o seu saber-fazer pedagógico, seja coerente com a sua autorreflexão mediante as experiências trazidas pelos alunos. Desta forma, a formação do professor proporciona a melhoria na aprendizagem do aluno, o professor contribui para a formação de saberes dos indivíduos em processo de aprendizagem, possibilitando experiências que servirão pra resoluções do cotidiano. Sendo que, o professor não é o detentor do saber, assumindo o papel de mediador, construindo o saber junto com o aluno, dando liberdade para o educando participar da própria construção.

Freire (1996) ainda afirma que a formação permanente do professor é de fundamental importância, na criação de uma reflexão crítica sobre a prática pedagógica.

RC: 105854

Disponível em: https://www.nucleodoconhecimento.com.br/educacao/autonomia-do-educando 
Colaborando no processo de aprendizagem e formação cidadã. Essa contribuição se dará do professor como mediador da aprendizagem, a fim de modificar a relação de dependência e contribuir para a autonomia do educando.

É nesse contexto da formação continuada que o professor transforma as suas habilidades e competências éticas em favor do ser humano a ser construído com suas especificidades críticas. Essa ética deve estar impregnada nos pensamentos, ações e práticas docentes, para que o convívio seja a presença dos seres com ele próprio, porém de forma harmoniosa e libertária. E partindo desse pressuposto que a história continua a ser construído, porém, de maneira respeitosa e crítico-reflexivo ampliandose a dimensão do ontem, do hoje e do amanhã.

Segundo Sacristán (1999), as relações sociais e culturais influenciam na prática docente do professor. Sendo a formação do educador essencial na construção do saber e aprendizado do aluno. Sendo importante, o professor estar em constantes estudos, para envolver as adversidades; se atualizar com as novas ferramentas tecnológicas; pois como o mundo está em constantes modificações, surgirão novas situações que precisarão ser compreendidas.

A reflexão sobre a teoria e a prática gera o determinismo dos conceitos e vivências possíveis para a transformação e formação dos seres diferentes, mas com os procedimentos de princípios organizados pelo professor, o que implicará nas ações formativas dos alunos.

Demo (2007), acrescenta que o investimento na qualidade da aprendizagem do aluno é também investir na qualidade do professor, que quando este se qualifica aprende a exercer melhor sua profissão, trazendo grandes resultados para educação e consequentemente mudanças sociais.

Essas formações serão reconstruções para os saberes ensinados de forma clara e objetiva. Porque o sentido de educar reflete no processo de aprendizagem, ou seja, na formação ética de quem ensina e de quem aprende. Por isso é importante pensar 
coerente com as práticas, em razão da segurança quando as argumentações dos discursos do ensino. Os sujeitos mediadores do ensinar devem pensar com respeito, para que haja entendimento reflexivo e crítico nas posturas de quem aprende.

Para Saviani (1986) o cidadão tem direitos e deveres, habilitado para viver em sociedade. Desta forma, o professor tem grande responsabilidade na formação de cidadãos, colaborando para o processo de ensino e aprendizagem.

Indiscutivelmente o discurso teórico do professor deve estar entrelaçado com a prática para melhor condicionamento e direcionamento para que aconteça de fato, os processos metodológicos autônomos. Pois, o professor, é aquele que pensa, cria, recria e avalia os seus fazeres em sala de aula, assumindo-se como um ser criativo através das experiências diversas, das culturas, no universo escolar.

Libânio (2004) afirma que a prática do professor também está relacionada com as experiências construídas em todo o ambiente escolar. Um professor que compartilha experiências, aprende compartilhando sua profissão, seus problemas no contexto de trabalho. Um problema vivenciado por um colega pode já ter sido vivenciado por outro que seguiu uma estratégia que deu certo.

É necessário que o professor esteja disposto a compartilhar experiências e aprender com outros colegas de profissão. O saber é constante e sempre pode-se aprender coisas novas. Uma situação adversa já pode ter sido vivenciada e resolvida em outro contexto e tempo. O diálogo entre profissionais é fundamental na compreensão de diferentes situações e resoluções de problemas.

O presente artigo pressupões as inúmeras transformações praticadas pelos docentes em formações continuadas para a realização de evidentes resultados satisfatórios e condizentes com o exercício da educação pública de qualidade. Portanto, se faz necessário que a formação contínua dos docentes, sejam de cunho qualitativo, principalmente para desenvolver metodologias de reinserção dos alunos na escola, e 
que os possibilite segurança, bem-estar e senso crítico para as transformações no seu cotidiano.

De acordo ainda com Libânio (2004) a necessidade da formação contínua para os docentes tem fundamental importância para o aprimoramento do desempenho das práticas educativas cujo intuito será de oferecer consistência e determinação teórico para o preparo dos alunos em sala de aula.

A formação docente é por excelência o fazer pedagogicamente em prol dos educandos, considerando a multiplicidade das atitudes para os fazeres específicos no âmbito escolar.

O termo formação continuado vem acompanhado de outro, a formação inicial. A formação inicial refere-se ao ensino de conhecimentos teóricos e práticos destinados à formação profissional contemplados por estágios. A formação continuada é o prolongamento da formação inicial, visando o aperfeiçoamento profissional teórico e prático no próprio contexto de trabalho e o desenvolvimento de uma cultura geral mais ampla, para além do exercício profissional. (LIBÂNEO, 2004, p. 227).

É notório que quando se aprende mais, é possível ensinar com mais prazer e determinação e autonomia. Portanto, na formação do professor, importa a vontade de transformar para fazer o educando crescer, superando os medos e inseguranças, daí segue para se fazer um ser de coragem. Aprender a aprender para não transferir conhecimentos, mas para construir pontes para as possibilidades existentes do saber do conhecimento.

Conforme afirma a lei de LDB 9.394/96 no art. 13, da importância de se zelar pela aprendizagem dos alunos. Sendo papel do professor o compromisso do ensino e comprometimento com a aprendizagem dos educandos (BRASIL, 1996).

Afinal, professor e alunos são inseridos num contexto presente em face a história que constroem, mesmo sabendo que os obstáculos são as pedras no caminho, esses seres se posicionam como sujeitos de luta e combate, com ética e respeito para a

RC: 105854

Disponível em: https://www.nucleodoconhecimento.com.br/educacao/autonomia-do-educando 
obtenção de resultados positivos. Sendo os saberes são fundamentais no que diz respeito às dimensões das práticas efetivadas, para a caracterização do melhor desempenho em sua essência.

Freire (1996) Ensinar exige competência e especificidade, no que diz respeito à democracia das interrelações entre docente e discente. Para o docente adquirir formação e autonomia, é preciso ser curioso e ter coragem para observar os comportamentos e fazer análises de pesquisa que envolvam os seus alunos no exercício da prática da liberdade.

Partindo das reflexões da condição dos seres humanos, surgem as indagações e curiosidades de conhecer, aprender mais e mais para a transformação da atual realidade. Sendo assim, o professor ensina para que o aluno aprenda a partir da construção, a se construir e a se reinventar progressivamente. É importante essa relação mútua de afetividade necessária entre professor e alunos, que juntos podem promover igualdades quanto ao ensinar e aprender para produzirem esperanças nas buscas e alternativas condizentes com as experiências de vida.

\section{A LEITURA NA FORMAÇÃO CONTINUADA DO PROFESSOR E AUTONOMIA DO EDUCANDO}

Segundo Raimundo (2007, p. 112), "O leitor que teve contato com a leitura desde cedo dentro de sua casa é diferenciado ao saber reconhecer os signos com maior facilidade que um aluno que teve seu primeiro contato ao entrar na escola."

O Professor que está em constantes capacitações e pesquisas, é um incentivador da leitura em sala de aula; pois antes é um ser envolvido pela leitura. Valorizando a autonomia do aluno na construção do saber.

A leitura é essencial à vida do ser humano. Estimula a criticidade, debate, diálogo, relação social. Começando pela leitura de mundo, as pessoas já são capazes de conhecer histórias e contar sua própria história. Os conhecimentos prévios antecedem

RC: 105854

Disponível em: https://www.nucleodoconhecimento.com.br/educacao/autonomia-do-educando 
a leitura da palavra, saberes construídos ao longo dos tempos, passados de geração para geração. Todo e qualquer conhecimento precisa ser valorizado, pois trata de saberes importantes para compreensão da sociedade.

O professor antes de tudo, precisa ter prazer na leitura. Todo o processo de aprendizagem tanto do educador como do aluno envolve a leitura. $\mathrm{O}$ educador como incentivador pode atuar estimulando o interesse do aluno no descobrimento do conhecimento. Uma participação importante na formação do educando, que necessita de estímulos para o desenvolvimento de habilidades.

[...] ler não é só caminhar sobre as palavras, e também não é voar sobre as palavras. Ler é reescrever o que estamos lendo. É descobrir a conexão do texto, e também como vincular o texto/ contexto com meu contexto, o contexto do leitor (FREURE, 1986, p. 22).

A leitura é fundamental no processo de aprendizagem não somente dos alunos, como dos próprios professores, que precisam está renovando seus conhecimentos, que é inacabado, e sempre tem algo novo para o professor aprender.

Por meio da leitura o professor tanto aprende, como, incentiva os alunos ao hábito de ler e curiosidade em descobrir e aprender novas coisas. Sendo importante nessa construção da autonomia do educando, incentivar o contato com a leitura, para desenvolvimento da criticidade e pesquisa. Por meio da formação do professor é aprendido que a leitura é indispensável no processo de aprendizagem, tanto dos profissionais da educação, como motivação dessa leitura na construção do saber dos alunos.

Durante muito tempo a leitura era entendida com um ato de decodificação, em que se convertiam letras em sons. Em função dessa visão, a escola formou uma quantidade muito grande de leitores inaptos a realmente compreenderem os textos lidos, embora os decodificassem.

Freire (2001) afirma que a leitura antecede a escola; e por meio de experiencias cotidianas já fazemos leitura de mundo.

RC: 105854

Disponível em: https://www.nucleodoconhecimento.com.br/educacao/autonomia-do-educando 
A escola tem papel fundamental no estímulo, tanto na valorização dos conhecimentos prévios dos educandos, como incentivo à leitura cientifica, para a construção do conhecimento formal e informal. E esse incentivo não pode ser algo imposto, mas espontâneo, no intuito de produzir seres pensantes, críticos, que podem questionar debater e construir.

Martins (2007), concorda com Freire, que o aprender a ler, antecede a fase escolar, e que $o$ ato de ler se dá logo nas nossas primeiras experiências e convívio com a leitura.

O estímulo à leitura tem sido objeto de preocupação constante no cotidiano escolar, alvo de inúmeros programas governamentais, além de alavanca do segmento do mercado editorial que mais tem crescido nos últimos anos. A verdade incontestável é que $o$ ato de ler é fundamental na formação do aluno e que considerável parcela de responsabilidade no desenvolvimento das habilidades de leitura recai sobre a escola.

Um bom professor é um professor leitor. Que tanto gosta de aprender novas coisas, e está em constantes formações, como incentiva a pesquisa e aprendizagem dos alunos.

Grossi (2008) afirma que pessoas que não são leitoras tem a vida restrita a comunicação, sendo fundamental 0 incentivo na formação de leitores para convivência social.

Ler deve ser considerado um ato indispensável. A prática da leitura, entendemos favorece a escrita, ou seja, quem tem o hábito de ler textos diversos, tem mais conhecimento e consequentemente condições de refletir sobre as ideias e formular opiniões. Com essa concepção de leitura, compreendemos que os alunos podem ampliar a capacidade de compreensão e expressão, tanto nas situações de comunicação oral quanto nas de comunicação escrita. É imprescindível inserir nos alunos a importância da leitura no sentido de torná-los bons leitores, garantindo assim, a participação plena na sociedade letrada, e com isso chamar a atenção para necessidade de leitores críticos, que sintam prazer na leitura.

RC: 105854

Disponível em: https://www.nucleodoconhecimento.com.br/educacao/autonomia-do-educando 
Para Soares (2002)

O fenômeno do letramento significa que já compreendemos que nosso problema não é apenas ensinar a ler e a escrever, mas é, também, e, sobretudo, levar os indivíduos a fazer uso da leitura e da escrita, envolver-se em práticas sociais de leitura e escrita. (SOARES, 2002, p. 18).

A capacidade de ler criticamente garante ao indivíduo condições de interferir no meio em que está inserido, podendo, inclusive, transformar a realidade. Para confirmar essa asserção, quando sugere que se o aluno ler sem prazer, sem o exercício da escrita, sem imaginação; se ele ler e nas jaz disso uma produção, nos exercícios, a palavra lida do outro, não há nisso nada que lhe possibilite uma intervenção sobre aquilo que historicamente está posto.

Gadotti (2004) vem destacar que é a capacidade que o sujeito possui de autodeterminar-se de autorrealizar-se, fazendo com que sua autoconstrução e compreensão crítica frente às questões sociais, exige que os docentes respeitem os saberes presentes em sala de aula e que esses saberes, construídos na prática social, sejam discutidos.

Diante das necessidades de adaptação e capacitação cada vez maiores impostas no ser humano pela vida moderna, a leitura e o conhecimento de mundo são fatores primordiais no que se refere a garantir ao indivíduo as condições apropriadas para viver dignamente. Diante disso, o compromisso firmado pelo professor deve ser incentivar, encorajar, criar situações, e com os mais diversificados textos para leválos ao interesse pela leitura, contribuindo assim para formar cidadãos capazes de atuarem com autonomia e responsabilidade no meio social em que vivem.

A formação do professor precisa contribuir no aprendizado do aluno, não somente em relação ao conhecimento adquirido pelo educador, mas as contribuições e motivações na construção da autonomia do educando. Assim como o professor precisa está renovando suas práticas pedagógicas, o aluno precisa entender que o conhecimento é inacabado, como afirma Freire (1996), e necessita constantemente buscar novos 
saberes. Entendendo que, a sociedade passa por grandes transformações, surgindo novas exigências, o que carece de constantes estudos para compreensão e intervenção na sociedade.

O ato de ler é fundamental tanto para os professores como para os alunos, e se essa leitura for sempre feita com um cunho crítico, o discente se tornará consciente de seu papel político-social, e se sentirá, inclusive, mais seguro em relação à melhor atitude a ser tomada por ele em determinada circunstância. Compreende-se que ler significa ainda conhecer, interpretar, decifrar, ir além da compreensão, fazendo intervenções para chegar a uma aprendizagem significativa, capaz de moldar mentes e transformar com o conhecimento real e ação do pensamento.

$\mathrm{Au}$ (2011) esclarece que os estudantes e professores tornam-se sujeitos que sabem ver a realidade, pensar criticamente sobre a realidade e admitir uma ação para mudar essa realidade.

A valorização da leitura, considerada num sentido mais amplo, advém de sua importância para a inclusão do sujeito em uma cultura letrada. Nesse sentido, o ato de ler ultrapassada, num primeiro patamar, habilidades de simples decodificação; e ancora-se, finalmente, na habilidade de compreender o que nos chega por meio das informações colhidas, analisando-as e posicionando-nos criticamente frente a elas. Todavia, nem sempre esse processo acontece de forma mais adequada.

Trabalhar com estratégias de leitura permite ao leitor ampliar e modificar os processos mentais de conhecimento, bem como compreender um texto. Compreender é a base para que todas as crianças se engajem completamente na leitura de livros de literatura e se tornem leitoras. (GIROTTO. SOUZA, 2010, p. 108).

Entende-se que pesquisas sobre a atividade de leitura são necessárias para interpretarmos o universo de representações socioculturais que integra o sujeito-leitor no mundo letrado do conhecimento. O interesse pela leitura está à educação, uma vez que o ato de ler influencia diretamente a aprendizagem de novos conhecimentos, sua importância.

RC: 105854

Disponível em: https://www.nucleodoconhecimento.com.br/educacao/autonomia-do-educando 
Conforme os parâmetros curriculares nacionais (BRASIL, 1999), formar um leitor incumbe formar um entendedor da leitura, que possam compreender além do que está escrito. E o professor tem esse papel de formar bons leitores; mais antes de tudo, precisa ser admirador da leitura, mostrando teoria e prática no processo ensinoaprendizagem.

A escola tem o papel de preparar o aluno para a vida. O ensino é de extrema importância nesse processo, para que venha se desenvolver seres pensantes, capazes de lutar por seus direitos e qualidade de vida. Sendo a leitura um recurso essencial na interpretação e compreensão do mundo. Esse estímulo e gosto pela leitura deve começar cedo, com a apresentação de livros do interesse dos alunos, para que os mesmos venham ter prazer e curiosidade em conhecimento. Viver conhecendo novos saberes é muito mais prazeroso, quando apreciamos coisas novas, nos instigamos a tentar novos desafios; e a acreditar na esperança de uma vida melhor, por meio do conhecimento e descobertas.

\section{ENSINAR PARA A CONSTRUÇÃO DA AUTONOMIA DO EDUCANDO}

Segundo Freire (1996) é importante que o ensino seja focado e direcionado para a construção da autonomia do educando. Sendo que, o ensino é para ser algo transformador e não teórico. Desenvolver a autonomia dos alunos está além de transferir conhecimentos, requer uma formação envolvendo as competências e habilidades. Sendo que, para esse ensino, o professor precisa estar envolvido em constantes pesquisas, se atualizando para atender as necessidades do educando.

O professor tem participação fundamental na construção da autonomia do educando. Sendo um facilitador e mediador da autonomia dos alunos, onde os educandos venham perceber a necessidade do aprender a cada dia. A relação professor-aluno é um ponto focal, onde é estabelecidos relações de confiança, de vínculos, e fortalecido o processo educativo, na articulação do conhecimento.

RC: 105854

Disponível em: https://www.nucleodoconhecimento.com.br/educacao/autonomia-do-educando 
À medida que o tempo vai passando, surge-se novas demandas. Numa aldeia global, em constantes modificações, novas ferramentas surgem, as tecnologias e as escolas precisam se adaptarem; adotando práticas inovadoras que possam transformar e melhorar o ensino com esses recursos. O modelo tradicional de educação, em que os alunos eram somente ouvintes, tornou-se impotente para a aprendizagem, visto que a participação dos alunos na construção do próprio conhecimento é eficaz, para enfrentamento das exigências da sociedade atual.

As ideais e reflexões tendem buscar ações capazes de transformar, conforme afirma Libânio (2002) que a teoria é o primeiro passo em que, primeiramente, o professor compreende as teorias a oferecer seu pensamento crítico para com os alunos para sua prática de ensino com instrumentos de ação.

Quando levamos em consideração que uma aprendizagem transformadora que tem como base a teoria crítica, torna-se importante para a reflexão de como esta pode ser usada para entender a prática de ensino e a aprendizagem, vemos que é necessário entender, também, que os resultados dessa reflexão precisam ser corporificados e que isso leva tempo, especialmente porque partem da premissa de uma modificação dos próprios parâmetros de compreensão e atuação no mundo, o que infere numa compreensão e aceitação das diferentes visões sobre o nosso meio e suas possíveis transformações.

Freire (2010) afirma que ensinar exige reconhecimento e assunção da identidade cultural, é preciso estabelecer uma intimidade entre os saberes curriculares relacionando com a vida social dos alunos.

O professor, antes de ensinar precisa compreender todo o contexto social em que o aluno vive. É necessário fazer essa leitura de mundo, para compreender as necessidades de cada um.

Sabendo que o simples ato de pensar sobre algo, sem a necessidade de se aprofundar, já pode ser denominado reflexão e essa reflexão ocorre na medida em 
que nos preocupamos em descrever e examinar um problema, vemos que a teoria crítica moderna, na qual se sobressai o racionalismo científico, apartou o conhecedor do conhecimento e também do conhecido. Assim, a Educação apresenta-se, como um veículo de promoção para uma mudança do pensamento, na percepção e nos valores que compõem uma teoria crítica. Segundo Freire (1996, p. 39):

A prática docente crítica, implicante do pensar certo, envolve 0 movimento dinâmico, dialético, entre o fazer e o pensar sobre o fazer. O saber que a prática docente espontânea ou quase espontânea, "desarmada", indiscutivelmente produz é um saber ingênuo, um saber de experiência feito, a que falta a rigorosidade metódica que caracteriza a curiosidade epistemológica do sujeito.

O processo de reflexão crítica sob a premissa de que uma formação crítica deve nos conduzir ao desenvolvimento humano, numa perspectiva cidadã, de modo que sejamos capazes de analisar a nossa realidade social, histórica e cultural, gera possibilidades para transformá-la, conduzindo professores e estudantes ao protagonismo no processo de ensino/aprendizagem.

Para Freire (1996, p. 40):

[...] é que, na formação permanente dos professores, o momento fundamental é o da reflexão crítica sobre a prática. É pensando criticamente a prática de hoje ou de ontem que se pode melhorar a próxima prática. $O$ próprio discurso teórico, necessário à reflexão crítica, tem de ser de tal modo concreto que quase se confunda com a prática. O seu "distanciamento" epistemológico da prática enquanto objeto de sua análise, deve dela "aproximá-lo" ao máximo.

Na visão docente, um professor crítico-reflexivo possui como principal característica a preocupação com consequências de cunho ético e moral de suas orientações no que se refere à prática social, além do desenvolvimento cognitivo do estudante. Considerando esse pressuposto, podemos entender o educador transformador crítico como sendo um agente que insere a escolarização diretamente na esfera política e vice-versa, concebendo os estudantes como atores críticos, através de diálogos e os argumentos, em favor de um mundo melhor para todas as pessoas. 
Parar e pensar em uma educação crítica é elevar para ações que transformadoras através da educação, ensinar sob esta visão, segundo Moreira (2010, p. 146): "Deve exercitar processos de emancipação individual e coletiva, estimulando e possibilitando a intervenção no mundo a partir de um sonho ético-político da superação da realidade injusta".

Estimular as capacidades de o aluno aprender, pela sua curiosidade e defender suas ideias e se relacionar com a teoria, dispõe ao educando a participação na prática pedagógica. Sendo assim, a autonomia desencadeada no aluno liberta para descobrir e aprender, dado que, politicamente concebida, é uma prática de construção de conhecimentos na perspectiva de que prepara e transforma para o mundo, uma atuação independente para a sociedade e inova a realidade que estão inseridos, igualmente como a pedagogia libertadora de Freire.

No tocante das práxis, como afirma Vásquez (2007) significa que toda práxis é atividade, mas nem toda atividade é práxis. Como se expressa, a prática se reporta de um exercício com um objetivo a ser buscado, onde toda práxis é uma atividade que deve impulsionar a reflexão de uma realidade que se pretender investigar para conhecer, é envolver a teoria na prática para que faça o aluno ter prazer ao realizar sua busca ativa.

Em conformidade, as práxis devem ser notadas como uma proposta de intervenção entre professor aluno, onde a problematização servirá como ponto de partida para novas concepções, ideias e hipóteses a serem trabalhadas com diálogo e reflexão, assim, alunos e professores se embalam na interpretação dos fatos decorrentes de uma realidade para conduzir uma ação que visa enaltecer conhecimento pautado em consequências éticas e morais da sociedade.

De acordo com Moreira (2010), esses educandos

[...] devem ser capazes de realizar uma leitura de mundo que thes permita compreender e denunciar a realidade opressora e anunciar a

RC: 105854

Disponível em: https://www.nucleodoconhecimento.com.br/educacao/autonomia-do-educando 
sua superação, com a construção de um novo projeto de sociedade e mundo a ser efetivado pela ação política. (2010, p. 98).

Neste pensar, os alunos devem ser incentivados a fazer uma leitura de mundo conduzida pela sua vivência e entender os fatores ao seu redor, entendendo e anunciando seus achados na sociedade, tendo em vista que este processo parte de ações transformadoras que criticam a posições e direcionamentos já existentes o mundo.

As transformações de mundo advêm do saber que são adquiridas ao longo da vida e não transferido, como afirma Paulo Freire (2003) que Conhecimento não se transfere, se cria, através da ação sobre a realidade. Contudo, o conhecimento vai sendo criado de acordo com as vivências conduzidas pelo grupo, onde cada pessoa tem uma conduta diferente cabendo ao indivíduo apropriar-se de criações como estímulos por meio da ação-reflexão transformadora, onde, por fim, se constrói o conhecimento. Ensinar para esta proposta de moldar o aluno a ser crítico é desencadear um processo de imaginação

Ao definir-se diante dos problemas e atuar consequentemente, considerando-os como situações que estão além de nossas próprias intenções e atuações pessoais, para incluir sua análise como problemas que têm sua origem social e histórica (CONTRERAS, 2002, p. 163).

Nesse sentido, o professor crítico, reflexivo considera a voz dos estudantes, atribuindo-Ihe sentido e significado de estar no mundo, permeando as suas ações no que se refere à sua própria aprendizagem, à escola e à sociedade. Logo, professores e estudantes percebem-se como agentes transformadores e passam a se considerar atuantes nesse processo de transformação e concebem a importância da coragem e da vontade de mudar suas realidades, a fim de proporcionar meios para uma redefinição da escola. Assim, o uso de uma linguagem crítica, que orienta o processo reflexivo, torna-se importante para a formação de professores e alunos conscientes do seu agir, mediante o processo de aprendizagem.

RC: 105854

Disponível em: https://www.nucleodoconhecimento.com.br/educacao/autonomia-do-educando 


\section{CONSIDERAÇÕES FINAIS}

Com a elaboração desse artigo concluímos que o docente precisa ter uma prática pedagógica na qual suscite nos discentes a criticidade, curiosidade, precisa explorar os conhecimentos prévios e valorizar a realidade que ele está inserido, criar possibilidades para que a aprendizagem aconteça.

O processo de ensino necessita de pesquisa, o professor precisa pesquisar para elaborar as aulas tornando a aula mais atrativa e introduzindo mais conhecimento para os discentes.

Retomando a questão norteadora: Qual a participação do professor na construção da autonomia do aluno? Constatou-se que o professor como mediador do conhecimento tem participação importante na formação e construção da autonomia do educando. Uma aula atrativa e criativa, onde é valorizado a escuta do educando, a reflexão e criticidade, e o incentivo da criação do saber, além de estabelecer relações dialógicas onde se constrói saberes e se aprende novas habilidades, espaço onde existe a participação ativa dos estudantes, na construção do conhecimento.

Uma educação que contribui para autonomia do educando, valoriza o profissional que estuda junto com os alunos, a medida que se depara com situações novas e precisa aprender para ensinar. Um profissional em constantes formações continuadas no intuito de atender as necessidades dos alunos da atualidade.

Ensinar exige que o docente crie laços com os discentes, estimulando o ser humano viver no contexto social, é primordial vincular os laços a diálogos coerentes capazes de estimular as pessoas, os assuntos para a reconstrução dos conhecimentos e saberes a partir das suas próprias histórias gerando a compreensão de mundo desde as leituras prévias até as contemporâneas.

O ser humano está apto a aprender sempre diante das circunstâncias e contextos do passado e da realidade com plenas condições de transformações dialógicas e críticas

RC: 105854

Disponível em: https://www.nucleodoconhecimento.com.br/educacao/autonomia-do-educando 
a partir da vivência e experiência com o outro, de modo que se faça presente a ética e a conexão com os espaços ensinamentos e aprendizagens coletivas.

Por isso a importância de o docente receber uma formação que incentive o discente a está cada vez mais autônomo, aguçando sua capacidade crítica ou seja estimulando sua curiosidade, pois assim o conhecimento permanece consolidado.

No contexto da nossa atualidade o professor precisa se dá conta de que deve avançar seus conhecimentos e leitura de acordo com as tecnologias para isso é necessário que este professor seja um leitor das novas tecnologias e de mundo e repense a sua prática transmitindo para o discente com segurança estimulando-o as novas aberturas da tecnologia para que este não fique aquém dos avanços midiáticos.

Por esta razão a formação do professor precisa está orientada para torná-lo em um pesquisador, para assim se aprofundar nas temáticas de estudo incentivando sua curiosidade e dos alunos.

A aprendizagem precisa estar voltada para um conhecimento transformador com base na criticidade e na reflexão, se preocupando em causar no aprendiz um conhecimento verdadeiro e questionador, considerando também seu meio social. Sabendo que um aluno que possui autonomia aprende a ser crítico e se impor na sociedade como ser pensante, ativo capaz de resolver problemas e contribuir para uma sociedade mais justa. Nesse caso a participação tanto do professor como da escola é tornar o aluno participativo na sociedade, para que possa desfrutar dos seus direitos como cidadão e contribuir para uma sociedade melhor.

A formação contínua favorece a autonomia para suas práticas metodológicas frente aos alunos para que estes adquiram conhecimentos transformadores e que sejam capazes de mudar o cenário da sociedade com reflexões, críticas, ações resistentes, afetuosas e importantes de forma coletiva.

RC: 105854

Disponível em: https://www.nucleodoconhecimento.com.br/educacao/autonomia-do-educando 
Vimos que o docente tem um papel importante que é de identificar os seus conhecimentos através das leituras diversificadas, bem como de cursos, para assim ocorrerem as intervenções e transformações práticas que envolvam o respeito o compromisso de cada ser em busca da qualidade do ensino e aprendizagem discorrendo e transportando saberes para além da sala de aula. Portanto, se faz necessário a necessidade de que o docente e discente caminhem juntos em busca da construção e reconstrução dos novos conhecimentos e suas praticidades eficazes e eficientes.

A formação como prática docente deve ter como base a autonomia dos discentes, precisa preparar o professor para valorizar a realidade que o discente está inserido, levar essa realidade para a sala de aula e incluir nos conteúdos. Através dos seus conhecimentos do senso comum mostrar os saberes científicos.

Diante dessa conjuntura da realidade, a escola tem um fundamental e marcante papel de estar presente nesse procedimento com o ensino de qualidade para que sejam desenvolvidos nos alunos mentes pensantes criativas e aptas a discussão para as práticas de lutas por direitos e deveres que lhe serão assegurados. Portanto persistir no gosto e estímulo pela leitura torna a visão de mundo amplo, capaz de atender as curiosidades e os anseios de uma vida mais digna através dos conhecimentos, o que dar prazer e desperta o ser humano, seja na condição de professor ou de aluno a experimentar o novo para enfrentar os desafios existentes na esperança de uma vida digna e saudável.

O docente precisa receber uma formação que o transforme em um educador que respeite a raça, o gênero, a classe, a identidade cultural do outro, aceite o novo sendo assim capaz de passar essa autonomia para o discente.

Diante do contexto apresentado o artigo influencia o professor para a ótica de mundo, focando o seu tempo e estímulos através das leituras, bem como da formação contínua para que se processe a construção da autonomia no tocante às diretrizes 
atuais e global para que dessa forma o professor seja um espelho para o aluno atingir o hábito da leitura também despertando para a visão crítica da sua realidade.

Portanto, a formação continuada do professor abre espaços e caminhos para os saberes éticos e científicos, na constante e conflituoso versos do mundo em movimento. Daí a contribuição necessária do professor para aprender e transmitir os saberes para o aluno e conduzindo novos conhecimentos e autonomia para serem capazes de reconstruir suas atitudes através de pensamentos críticos para a intervenção na sociedade em benefício do bem comum para todos.

No entanto, para que o docente oportunize uma aprendizagem que torne o sujeito autônomo precisa criar possibilidades que os discentes sejam incentivados a pesquisarem, a serem curiosos, a terem responsabilidade e a exporem suas opiniões estimulando assim sua capacidade crítica. Sabendo que ensinar não é transferir conhecimento, mas permitir a construção do indivíduo, como ser social, capaz de pensar e intervir na sociedade. Sendo uma ação de influência a serviço das mudanças sociais. Como afirma Freire (1996) a formação do professor deve ser uma reflexão sobre a prática pedagógica, investindo na educação de forma que venha trazer resultados de aprendizagem para os alunos.

\section{REFERÊNCIAS}

AU, W. Lutando com o texto: contextualizar e descontextualizar a pedagogia crítica de Freire. In: APPLE, Michael W; AU, Wayne; GANDIN, Luís A. Educação crítica: análise internacional. Porto Alegre: Artmed, 2011.

BRASIL. Lei o 9394, de 20 de dezembro de 1996. Estabelece as diretrizes e bases da educação nacional. Diário Oficial da União, Brasília, 23 dez. 1996.

BRASIL. Ministério da Educação. Parâmetros Curriculares Nacionais: língua portuguesa. Brasília: SEED, 1999.

CONTRERAS, José. Autonomia dos professores. São Paulo: Cortez, 2002 RC: 105854 
DEWEY, J. Como pensamos. 3. ed. São Paulo: Companhia Editora Nacional, 1959.

DEMO, Pedro. É preciso estudar. In A. M. de Brito. Memórias de formação: registros e percursos em diferentes contextos. Campo Grande: Ed. Da UFMS, 2007.

FREIRE, Paulo. Política e educação. São Paulo: Corte, 1993.

(1996) Pedagogia da Autonomia: saberes necessários à prática educativa. São Paulo: Paz e Terra, 1996.

(2010) Pedagogia da Autonomia. Rio de Janeiro: Paz e Terra, 2010.

FREIRE, Paulo \& SHOR, Ira. Medo e Ousadia: o cotidiano do professor. Rio de Janeiro: Paz e Terra, 1986.

FREIRE, P. A importância do ato de ler. São Paulo: Cortez, 2001.

(2011) Pedagogia do Oprimido. 50ed. São Paulo: Paz e Terra, 2011.

GADOTTI, Moacir. Escola cidadã. 10 ed. São Paulo: Cortez, 2004.

GIMENO SACRISTÁN, J. Poderes Instáveis em Educação. Porta Alegre: ARTMED, SUL 1999.

GIROTTO, C.G.G.S.; SOUZA, R.J. Estratégias de leitura: para ensinar alunos a compreender o que leem. In: SOUZA. Renata Junqueira (org). Ler e compreender: estratégias de leitura. Sampina, SP: Mercado de Letras, p.108, 2010

GROSSI, Gabriel Pilar. Leitura e sustentabilidade. Nova Escola. São Paulo, SP, nำ18, 2008.

LIBÂNEO, José Carlos. Organização e gestão da escola: teoria e prática. GOIÂNIA: ALTERNATIVA, 2004. 
- Reflexividade e formação de professores: outra oscilação do pensamento pedagógico brasileiro? São Paulo, Cortez Editora,2002.

MARTINS, Maria Helena. O que é leitura. São Paulo: Brasiliense, 2007.

MOREIRA, C.E. Criticidade. IN: REDIN, E.; STRECK, D.R.; ZITKOSKI, J.J. (Org.). São Paulo, Moraes, 2010, p.98.

RAIMUNDO, A. P. P. A mediação na formação do leitor. In: CELLI - COLÓQUIO DE ESTUDOS LINGUÍSTICOS E LITERÁRIOS, 3. 2007, Maringá.

SOARES, Magda. Linguagem e escola: uma perspectiva social. 17. ed. São Paulo. Ática, 2002. E-book.

SAVIANI, D. Educação, cidadania e transição democrática. In: COUVRE, Maria de Lourdes (org). Cidadania que não teos. São Paulo: Brasilienses, 1986.

VÁSQUEZ, Adolfo Sánchez. Filosofia da práxis. São Paulo: Expressão Popular, 2007.

Enviado: Setembro, 2021.

Aprovado: Janeiro, 2022. 